
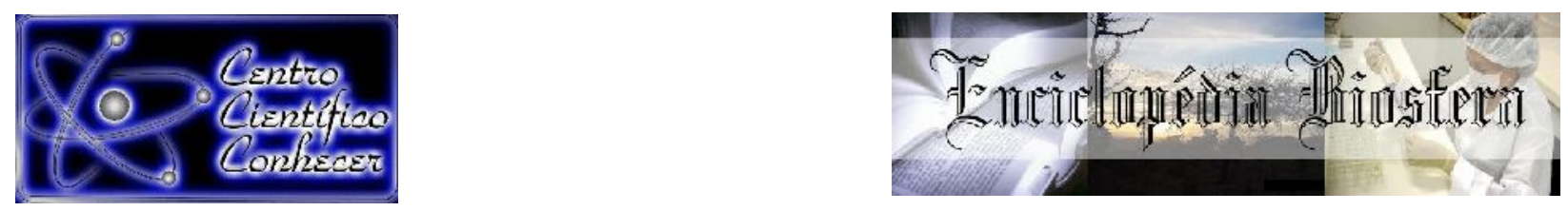

\title{
PARÂMETROS CLÍNICOS, BIOLÓGICOS E MOLECULARES NA RESPOSTA AO TRATAMENTO COM INTERFERON-BETA EM PACIENTES COM ESCLEROSE MÚLTIPLA
}

\author{
Samara Gema ${ }^{1}$, Enedina Maria Lobato de Oliveira ${ }^{2}$, Cristina Eunice Okuyama ${ }^{3}$ \\ Susana Nogueira Diniz ${ }^{3}$ \\ 1. Graduada em Biomedicina na Universidade Anhanguera de São Paulo, São Paulo, \\ Brasil \\ 2. Professora Doutora da Universidade Federal de São Paulo, Brasil \\ 3. Professora Doutora da Universidade Anhanguera, São Paulo, Brasil \\ (dinizsusana@gmail.com)
}

Recebido em: 22/09/2018 - Aprovado em: 23/11/2018 - Publicado em: 03/12/2018 DOI: 10.18677/EnciBio_2018B100

\begin{abstract}
RESUMO
A esclerose múltipla (EM) é uma doença auto-imune inflamatória do sistema nervoso central (SNC) que causa desmielinização seguida de remielinização incompleta. $O$ caráter auto-imune e a suspeita de que uma infecção viral pode estar envolvida na progressão da doença faz com que o interferon-beta recombinante seja um dos mais importantes tratamentos da esclerose múltipla. Essa terapia imunomodulatória tem demonstrado resultados satisfatórios que ilustram uma diminuição dos surtos e das exacerbações dos sintomas. Entretanto, tem sido notada uma grande diferença no perfil de resposta entre os pacientes tratados, que pode ocorrer devido a fatores genéticos e moleculares. A presença de fatores que modificam a ação da droga e, consequentemente, 0 desenvolvimento da doença, deve ser investigada intensivamente e anticorpos neutralizantes podem ser considerados como o principal motivo da diminuição da eficácia da terapêutica. Portanto, a busca por marcadores de resposta à terapia com interferon-beta em pacientes com esclerose múltipla tem uma grande importância no monitoramento da terapêutica, de modo a definir parâmetros na resposta a esse tratamento, para o prognóstico da doença. $O$ presente trabalho teve o objetivo de buscar critérios de resposta ao interferon-beta que possam distinguir pacientes, visando um possível prognóstico para a esclerose múltipla.
\end{abstract}

PALAVRAS-CHAVE: Biomarcadores, Esclerose múltipla, Interferon-beta

\section{CLINICAL, BIOLOGICAL AND MOLECULAR PARAMETERS IN THE RESPONSE TO THE INTERFERON-BETA TREATMENT IN MULTIPLE SCLEROSIS PATIENTS}

\begin{abstract}
Multiple sclerosis is an autoimmune inflammatory disease of the central nervous system that causes demyelination following of incomplete remyelination. The autoimmune characteristic and the suspect of viral infection involved on progression of the disease make that recombinant interferon-beta to be one of the most important treatments of multiple sclerosis. This immunomodulator therapy has demonstrated satisfactory results showing a decrease of relapses and of symptoms exacerbation. However, it has been observed a range of different response profiles between treated patients, that may be due to genetic and molecular factors. The presence of factors that modify the drug action and, consequently, the disease development, may
\end{abstract}


be intensively investigated, and neutralizing antibodies may be considered the major factor that reduce therapeutic efficacy. Therefore, the search for predictive markers for response to interferon therapy in patients with multiple sclerosis has great importance on the therapeutic monitoring to define parameters on the response to this treatment to the disease prognostic. The present study has the aim to search interferon-beta response criteria that distinguish responding from non-responding patients useful to a possible multiple sclerosis prognostic.

KEYWORDS: Multiple sclerosis, interferon-beta, biomarkers.

\section{INTRODUÇÃO}

A esclerose múltipla (EM) é uma doença inflamatória auto-imune do sistema nervoso central (SNC), que compromete a mielina. Este processo leva a um bloqueio ou atraso das informações enviadas pelo cérebro, e, consequentemente a diferentes sintomas neurológicos. A doença se manifesta por surtos intermitentes na forma clínica denominada remitente-recorrente, que pode evoluir para a forma secundária progressiva, ou se manifestar diretamente na forma progressiva primária (DENIC et al. 2011; MARQUES et al., 2018).

O mecanismo da EM permanece desconhecido, mas modelos experimentais apontam para um mecanismo auto-imune que pode se iniciar por mimetismo molecular, após persistência de um agente infeccioso ou por perda da tolerância celular para antígenos próprios. O mecanismo imunopatológico ainda é considerado como dependente da imunidade celular, com células T auto-reativas (YADAV et al., 2015). Conceitualmente a EM é considerada uma doença complexa, onde fatores ambientais e o perfil de susceptibilidade genética têm igual importância para desencadear mecanismos celulares que irão danificar a bainha de mielina, causando os sinais e sintomas clínicos observados na doença (MARQUES et al., 2018).

O diagnóstico se fundamenta em um conjunto de critérios clínicos e laboratoriais e a escolha do tratamento por drogas imunomoduladoras se baseia no número de surtos, na incapacidade neurológica e na carga lesional, com o objetivo de estabilizar a evolução da doença (KARUSSIS, 2014). Pelo fato do sistema imune estar altamente reativo e por haver suspeita de agente viral desencadeador do processo auto-imune, um dos tratamentos utilizados na EM é a administração de interferon-beta (IFN- $\beta$ ) recombinante. Este tratamento demonstrou melhoras nos sinais clínicos e na recorrência dos surtos da EM, mas apesar dos benefícios apresentados, a resposta ao tratamento imunomodulador é variável e imprevisível entre os pacientes, por isso a escolha adequada do tratamento para cada paciente é de extrema importância para a melhora dos sintomas e de sua qualidade de vida (SUARDÍAZ et al., 2016; BLANK; PRINZ, 2017).

O presente trabalho tem como objetivo revisar a EM e complementar as informações em relação ao tratamento com IFN- $\beta$ a seus pacientes, relatando seus efeitos e considerando os mecanismos de ação na tentativa de se buscar possíveis marcadores de predição à resposta ao tratamento com esse imunomodulador

\section{DESENVOLVIMENTO}

\section{Esclerose múltipla}

A EM é uma doença desmielinizante de caráter auto-imune do SNC que compromete a substância branca. O acometimento da substância branca ocorre justamente pela degeneração da camada proteolipídica protetora dos axônios, a mielina (MARQUES et al., 2018). A desmielinização é seguida de remielinização incompleta e inadequada, originando cicatrizes gliais que formam múltiplas placas ENCICLOPÉDIA BIOSFERA, Centro Científico Conhecer - Goiânia, v.15 n.28; p.1262 
disseminadas pelo SNC as quais são responsáveis pela denominação "esclerose múltipla". Essas placas são responsáveis pelos déficits neurológicos típicos da doença, que surge em forma de surtos, mas esse quadro pode evoluir e aumentar gradualmente a incapacidade, de forma que os déficits tornam-se permanentes e progressivos (NALAWADE et al., 2018).

Um dos primeiros relatos feitos sobre a EM ocorreu em 1868 quando Charcot fez uma descrição clássica da doença e observou a presença de células inflamatórias no líquor, substância branca e medula espinhal de pacientes com episódios recorrentes e intermitentes de disfunções neurológicas. Posteriormente, pesquisas envolvendo características genéticas passaram a ser desenvolvidas no intuito de examinar a etiologia (KARUSSIS, 2014). Os achados através de modelos experimentais da EM, encefalomielite auto-imune experimental (EAE), o envolvimento de linfócitos $T(L T)$, linfócitos $B(L B)$ e anticorpos bem como a melhora através de tratamentos imunossupressores são fatos que reforçam o caráter autoimune da EM e que se tornaram base para os estudos em relação à etiologia (FERNANDEZ et al., 2010; KARUSSIS, 2014).

Embora alguns países e populações sejam pouco afetados, pode-se dizer que a EM é uma doença de grande importância para o mundo por sua distribuição (MA et al., 2014). A EM geralmente se desenvolve em indivíduos com idade entre 20 e 40 anos e acomete aproximadamente duas vezes mais as mulheres do que os homens. No Brasil, segundo a Associação Brasileira de Esclerose Múltipla (ABEM) atualmente cerca de 35 mil brasileiros são portadores de EM (ABEM, 2018).

Em países desenvolvidos (fator que sugere a influência ambiental no desenvolvimento da doença), apresentam grande frequência, sendo grande parte do norte da Europa, norte dos Estados Unidos, sul do Canadá, sul da Austrália e Nova Zelândia as regiões de maior incidência, ou seja, 30 casos ou mais a cada 100.000 habitantes. O sul da Europa, o sul dos Estados Unidos, o Oriente Médio, a Índia e partes do norte da África e África do Sul são regiões consideradas de média prevalência (5 a 30 casos a cada 100.000 habitantes), em contrapartida, o Japão, a China e países da América Latina e América do Sul são regiões de baixa prevalência (menos de cinco casos a cada 100.000 habitantes) (FERNANDEZ et al., 2010; MA et al., 2014).

\section{Etiologia e patologia}

A etiologia da EM não é totalmente esclarecida, mas sabe-se que esta se desenvolve a partir de predisposição genética e que fatores ambientais possivelmente interferem em seu curso. Estudos populacionais demonstraram que a migração de pacientes com idade entre 15 e 16 anos que viviam em locais de alta incidência e migraram para região de baixa incidência ocasionou diminuição no risco em desenvolver a doença, de modo que em pacientes com idade superior a 16 anos essa migração não modificou o risco, esses fatos sugerem a interferência ambiental no desenvolvimento da EM durante a infância (FERNANDEZ et al., 2010; LUCAS et al., 2015).

Em 1933 foi mostrado que injeções de antígeno de cérebro e medula espinhal de coelhos em primatas causou inflamação no SNC e desenvolvimento de doença similar à EM, demonstrando que esta pode ser secundária a uma resposta contra antígenos estranhos (RIVERS et al., 1933). Entretanto nunca foram encontrados antígenos estranhos em pacientes com EM, enfatizando assim seu caráter autoimune. Foi determinado que a susceptibilidade genética à EM, assim como em muitas outras doenças auto-imunes, está relacionada a genes localizados na região 
cromossômica do antígeno leucocitário humano (HLA) - cromossomo 6, mais precisamente aos genes HLA-DR, DQ e $B^{\star} 08$, sendo em caucasianos o haplótipo HLA-DR 15, que em homozigose aumenta o risco à doença (relação dose-resposta). Devido a um mecanismo denominado "desequilíbrio de ligação", a presença do HLADR 15 está associada com a presença de genes da família de citocinas como fator transformador de crescimento (TGF) beta (TGF- $\beta$ ) e fator de necrose tumoral (TNF), além do gene CTLA-4 (antígeno associado ao linfócito $\mathrm{T}$ citotóxico), genes antagonistas de receptores de interleucina (IL) 1 (IL-1) e receptores de estrogênio. Não representando apenas risco à $E M$, os genes HLA também podem estar envolvidos na proteção, como é o caso do gene HLA-A201 (BOQUETT et al., 2018; MOHAJER et al., 2018). Recentemente, estudo demonstrou que o sequenciamento do exoma de pacientes com esclerose múltipla revelou variantes associadas com o curso da doença (GIL-VAREA et al., 2018).

Agentes infecciosos podem ser importantes indutores de resposta imune na EM, podendo desencadear um processo de mimetismo molecular para com os antígenos de mielina, principalmente a infecção viral, que é apontada como importante fator que pode estar associado ao desenvolvimento da resposta imune na EM. Vírus como o herpes simplex virus, estão relacionados a outras doenças auto-imunes por isso podem estar envolvidos na EM, sendo que os herpes virus são as famílias de maior probabilidade devido ao tropismo às células $\mathrm{T}$ e à latência, por isso epstein-barr vírus e human herpes virus também podem estar ligados à etiologia da EM, uma vez que o Human herpes virus 6 infecta os oligodendrócitos (LEIBOVITCH; JACOBSON, 2014).

Devido ao fato da EM acometer duas vezes mais as mulheres que os homens, hormônios sexuais também podem estar envolvidos em sua etiologia. Essa hipótese foi reforçada por estudos que demonstraram a diminuição dos surtos após a gravidez e aumento durante o período menstrual. Observou-se também um aumento da atividade da doença através da ressonância magnética $(R M)$, no aumento do nível de estradiol, em contrapartida o hormônio masculino testosterona pode exercer um efeito protetor. Apesar dessas pesquisas, o envolvimento de hormônios sexuais na EM não é totalmente comprovado, mas sabe-se das ações dos estrógenos como pró-inflamatórios e adjuvantes da secreção de algumas citocinas, o que poderia influenciar o desencadeamento da EM (YSRRAELIT; CORREALE, 2018).

Segundo Lucas et al. (2015), a baixa exposição ao sol e a falta de vitamina D também podem agravar o quadro da EM, pois ocasiona o aumento da produção de melatonina, o que leva ao aumento da resposta mediada por LT helpers (Th) do tipo 1 e, consequentemente, à intensificação do processo inflamatório. Portanto, a baixa exposição ao sol junto a fatores de predisposição genética pode representar um importante mecanismo de desenvolvimento da EM, mecanismo o qual pode ser um dos motivos que determina a alta incidência da doença em países com pouca luz solar.

O estilo de vida dos pacientes também pode influenciar diretamente o curso da doença, já que a industrialização pode ser um forte determinante no desenvolvimento da EM, principalmente levando-se em consideração o fato da EM ser mais prevalente em locais desenvolvidos e industrializados, portanto hábitos urbanos como: tabagismo, exposição a solventes e mudanças na dieta podem ser fatores de alto risco, embora não exista nenhuma evidência (ALFREDSSON; OLSSON, 2018). 


\section{Abordagem imunológica}

Estudos demonstraram que após injeção de antígenos da mielina, mais precisamente proteína básica da mielina (PBM) ou proteolipoproteína (PLP) em animais suscetíveis, ocorre o desencadeamento da EAE. O mecanismo da EAE em camundongos susceptíveis se inicia pela ligação da molécula do complexo principal de histocompatibilidade (MHC) de classe II (MHCII) ao antígeno determinante, o qual deve ser injetado no animal susceptível para que este venha a desenvolver a doença. A ligação da molécula MHC II ao antígeno forma o complexo MHCantígeno, onde LT Cluster determination 4 (CD4+) do tipo I, também chamados de LTh 1, se ligam a esse complexo via seus receptores de antígeno, os receptores de célula T (TCR), e são ativados, iniciando a resposta imune (ABBAS et al., 2015; HAMANA et al., 2018).

O fato de que a transferência desses linfócitos em animais sadios levou ao desenvolvimento da doença, leva a conclusão de que essa doença é mediada por LTCD4+ do tipo 1, diferentemente dos anticorpos, que ao serem transferidos não têm a capacidade de desencadear a doença em animais sadios. Os linfócitos Th1 ativados promovem a secreção de IFN-gama (IFN- $\gamma$ ), que por sua vez ativam os macrófagos, os quais são, também, responsáveis pelo processo de desmielinização (ABBAS et al., 2015; HAMANA et al., 2018).

Para que ocorra a ativação dos LTCD4+, são necessários, além da ligação e apresentação dos antígenos via MHC II, HLA em humanos, mecanismos de sinalização secundários (sinais coestimulatórios), sendo que alguns estudos demonstraram que a ligação das células $\mathrm{T}$ ao complexo MHC-antígenos, na ausência de sinais coestimulatórios, ocasiona a inativação de LT e consequente desenvolvimento de tolerância antígeno-específica, ou seja, anergia clonal. Portanto, a injeção de complexos solúveis purificados de MHC-antígenos próprios poderia funcionar como tratamento de doenças auto-imunes quando os auto-antígenos são conhecidos, pois ocorreria anergia dos LT na ausência de coestimulação, diminuindo assim os danos ou a gravidade da doença, ocasionados pelo mecanismo autoimune. Essa teoria foi confirmada, pois a injeção de complexos MHC-antígenos da ielina (PBM/PLP) diminui a gravidade da EAE e também após a injeção de nanopartícula carregada de peptídeo de mielina ligado ao complexo MHC, CD47 e outras moléculas regulatórias (PEI et al., 2018). Além das moléculas HLA II, as moléculas HLA I também estão envolvidas agindo de maneira independente, através da modulação da atividade de células natural killer (NK) e LT Cluster determination 8 (CD8+) (JELCIC et al., 2018).

Como já citado anteriormente, uma infecção prévia pode ser responsável pela indução de reação cruzada envolvendo antígenos próprios devido ao mimetismo molecular, sendo que LT ativados nos órgãos linfóides secundários por epitópos do patógeno migram ao SNC, através da barreira hematoencefálica (BHE) e se diferenciam após reconhecerem antígenos próprios na superfície de células apresentadoras de antígenos (APC) no SNC. As APCs do SNC apresentam antígenos próprios por motivos não totalmente esclarecidos, sendo que após o processamento de antígenos próprios, elas saem do SNC também através da BHE e migram aos órgãos linfóides secundários ativando os LT naive (linfócitos virgens, inativados, que nunca encontraram o antígeno) que lá se encontram. Esses linfócitos ativados e diferenciados migram para o SNC onde iniciam o processo de autoimunidade. Esses mecanismos podem ocorrer de maneira simultânea, considerando a hipótese de a infecção viral estar envolvida na EM (WERGELAND et al., 2018). É importante ressaltar que a migração das células para o SNC através da BHE pode 
ser mediada por proteínas de adesão como alfa-4 integrina, já que em modelos experimentais de EAE verificou-se que a presença de anticorpos contra essa proteína proporciona redução de surtos recorrentes (TIETZ et al., 2018).

\section{Aspectos clínicos}

Geralmente a EM se inicia através de sintomas indefinidos e difíceis de serem relacionadas à doença, isso se deve ao fato de não serem específicos o que leva à semelhança a outras doenças. Esses sintomas inespecíficos podem desaparecer sem deixar sequelas e os mais comuns são: fraqueza, distúrbios sensitivos e neurite óptica, por exemplo, o que dificulta o diagnóstico da doença. Os sintomas que caracterizam a EM recorrente-remitente (EMRR) inicialmente são reincisivos e frequentes, mas apesar desse quadro (dependendo da frequência dos surtos), as remissões podem não ocorrer ou ocorrer de maneira incompleta e agravar o quadro clínico do paciente (SOELBERG SORENSEN, 2017).

A EMRR é a forma mais comum da doença, já que aproximadamente $85 \%$ dos pacientes a desenvolvem no início. Os surtos apresentados nessa forma clínica podem reincidir no período de meses ou os intervalos entre os mesmos podem levar anos, variando entre os pacientes. De acordo com esses intervalos é possível prever o curso da EMRR, pois em pacientes que apresentam surtos com intervalos longos, geralmente o quadro é estável (SOELBERG SORENSEN, 2017).

Além da forma recorrente-remitente a EM pode se apresentar, já inicialmente, na forma progressiva primária onde diferentemente da EMRR, os déficits são evolutivos com piora do quadro no decorrer do tempo, não havendo remissões. A EM progressiva primária (EMPP) representa $10 \%$ dos casos e geralmente acomete indivíduos com idade superior a 40 anos (MCKAY et al., 2015).

A terceira forma clínica da doença é a EM secundária progressiva (EMSP), que evolui a partir da EMRR e ocorre em $40 \%$ dos pacientes. A EMSP se inicia a partir da EMRR, em média 15 anos após o início de seus sintomas, apresentando uma progressão lenta e gradual e piora dos sintomas neurológicos caracterizada pela incapacidade crônica (DE ANGELIS et al., 2018).

\section{Diagnóstico}

Devido às dificuldades encontradas para que seja realizado um diagnóstico coerente da EM, foram definidos critérios pelo "Painel Internacional no Diagnóstico da Esclerose Múltipla" os quais ficaram conhecidos internacionalmente como critérios de McDonald. Esses critérios visavam, principalmente, criar um esquema diagnóstico padrão para a EM que pudesse ser utilizado através de práticas neurológicas, evitando a incidência de falsos positivos (DALTON et al., 2002). Primeiramente os critérios de McDonald baseavam-se na imagem por RM, história neurológica do paciente e exames laboratoriais, porém considerando a disseminação das lesões em tempo e espaço e a análise do líquor, houve algumas controvérsias já que os critérios não enfatizavam esses fatores até então. Ao longo dos anos, o acometimento de outras populações exigiu uma adequação e validação destes critérios de acordo com o público alvo. Assim, com os avanços científicos novas orientações vêm sendo atualizadas para a aplicação de clínicos e pesquisadores. Por esses motivos, em 2005 (POLMAN et al., 2005), em 2010 (POLMAN et al., 2011) e em 2017 (THOMPSON et al., 2018) os critérios de McDonald sofreram reformulações.

A RM é extremamente útil no diagnóstico da $\mathrm{EM}$ e funciona como base e referência para o tratamento da doença. Essa importância se deve à alta sensibilidade do método na detecção de lesões, já que esta detecta alterações em 
aproximadamente 87 a $100 \%$ dos pacientes, sendo que na tomografia computadorizada essas detecções caem para 30 a $52 \%$ dos pacientes (PRZYBEK et al., 2015).

As placas disseminadas, típicas da EM, são encontradas em todas as partes da medula e do cérebro, onde também podem ser encontradas lesões que, geralmente, se agrupam ao redor dos ventrículos e também nos nervos ópticos. Essas características são observadas por cortes cerebrais, mas também são facilmente identificadas através de RM. O diagnóstico da EM por meio de RM deve ser somado à história clínica do paciente, de modo a associar os sintomas com a imagem, pois mesmo não sendo fáceis de identificar e relacionar à doença, os sinais e sintomas não relacionados anatomicamente e servem de base para o diagnóstico da EM (PRZYBEK et al., 2015).

As imagens T2 têm sido padronizadas para a demonstração das áreas comprometidas, já que a distribuição e a morfologia das placas são bem identificadas e podem servir como dados confirmatórios ou sugestivos de EM, apesar de poderem ser confundidas a outras lesões como doenças vasculares, por exemplo. Mas além das imagens T2, as imagens T1 ponderadas também fazem parte do diagnóstico da EM e permitem a observação dos chamados "buracos negros", ou seja, regiões hipodensas que geralmente se superpõem às regiões correspondentes às cicatrizes gliais (THOMPSON et al., 2018).

Através do Quadro 1 e Quadro 2 é possível comparar os critérios de McDonald originais e atualizados, levando em consideração a disseminação de lesões da EM por tempo e espaço:

QUADRO 1 - Critérios de imagem por RM na ilustração de disseminação das lesões em tempo.

\begin{tabular}{|c|c|c|c|}
\hline $\begin{array}{l}\text { Critérios de } \\
\text { McDonald } \\
\text { (original) }\end{array}$ & $\begin{array}{l}\text { Alterações dos } \\
\text { critérios de } \\
\text { McDonald } \\
\text { (2005) }\end{array}$ & $\begin{array}{l}\text { Alterações dos } \\
\text { critérios de } \\
\text { McDonald } \\
(2010)\end{array}$ & $\begin{array}{l}\text { Alterações dos } \\
\text { critérios de } \\
\text { McDonald } \\
(2017)\end{array}$ \\
\hline $\begin{array}{l}\text { DLT pode ser } \\
\text { comprovado por: } \\
\text { a) Pela presença de pelo } \\
\text { menos uma lesão que } \\
\text { aumenta o gadolínio no } \\
\text { cérebro na MRI } \\
\text { realizada pelo menos } 3 \\
\text { meses após o início dos } \\
\text { primeiros sintomas } \\
\text { clínicos*. Esta lesão não } \\
\text { deve ser a responsável } \\
\text { pelos sintomas clínicos. } \\
\text { b) Pela presença de } \\
\text { uma nova lesão } \\
\text { hiperintensa em T2 ou } \\
\text { uma lesão potenciadora } \\
\text { de gadolínio na segunda } \\
\text { MRI realizada não antes } \\
\text { de } 3 \text { meses após a } \\
\text { primeira. }\end{array}$ & $\begin{array}{l}\text { DLT pode } r \text { ser } \\
\text { comprovado de } 2 \\
\text { formas: } \\
\text { a) Pela presença de } \\
\text { lesão potenciadora de } \\
\text { na MRI realizada pelo } \\
\text { menos } 3 \text { meses após o } \\
\text { início dos primeiros } \\
\text { sintomas clínicos. Esta } \\
\text { lesão não deve ser a } \\
\text { responsável pelos } \\
\text { sintomas clínicos. } \\
\text { b) Pela presença de } \\
\text { uma nova lesão } \\
\text { hiperintensa em T2 na } \\
\text { próxima MRI, se a } \\
\text { anterior foi realizada } \\
\text { pelo menos } 30 \text { dias } \\
\text { após o início dos } \\
\text { primeiros sintomas } \\
\text { clínicos. }\end{array}$ & $\begin{array}{l}\text { DLT pode ser } \\
\text { comprovado de } 2 \\
\text { formas: } \\
\text { a) Pela presença de } \\
\text { uma nova lesão } \\
\text { hiperintensiva em T2 } \\
\text { ou uma lesão } \\
\text { potenciadora de } \\
\text { gadolínio na próxima } \\
\text { MRI. O tempo do } \\
\text { exame de MRI } \\
\text { anterior não é } \\
\text { importante. } \\
\text { b) Pela presença de } \\
\text { ambas as lesões que } \\
\text { aumentam e não } \\
\text { realçam o gadolínio } \\
\text { na primeira MRI. O } \\
\text { tempo do exame de } \\
\text { MRI não é } \\
\text { importante. }\end{array}$ & 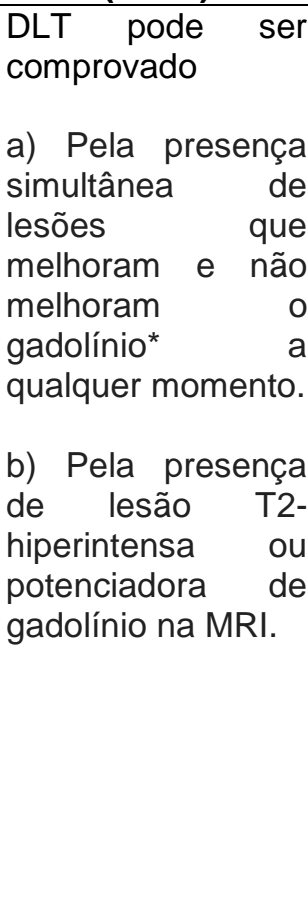 \\
\hline
\end{tabular}

Fonte: Adaptado de Przybek et al. (2015) e de Thompson et al. (2018). 
QUADRO 2 - Critérios de imagem por RM na demonstração de anormalidades e disseminações em espaço.

\begin{tabular}{|c|c|c|c|}
\hline $\begin{array}{l}\text { Critérios de } \\
\text { McDonald } \\
\text { (original) }\end{array}$ & $\begin{array}{l}\text { Alterações dos } \\
\text { critérios de } \\
\text { McDonald } \\
\text { (2005) }\end{array}$ & $\begin{array}{l}\text { Alterações dos } \\
\text { critérios de } \\
\text { McDonald } \\
(2010)\end{array}$ & $\begin{array}{l}\text { Alterações dos } \\
\text { critérios de } \\
\text { McDonald } \\
(2017)\end{array}$ \\
\hline 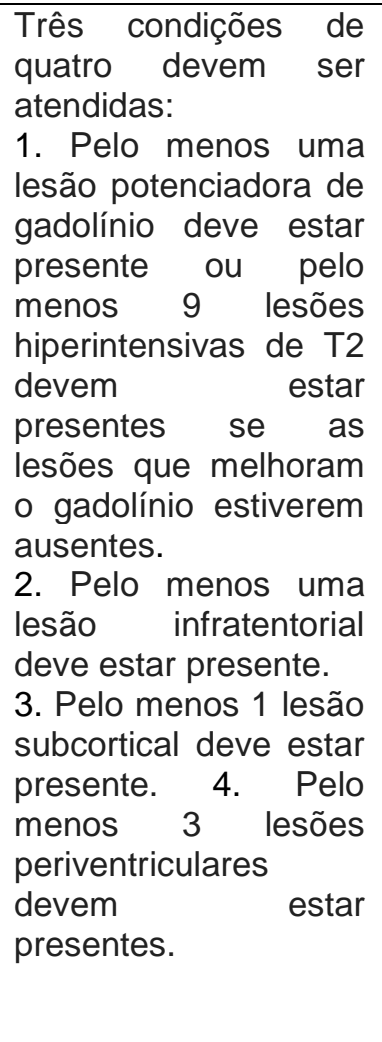 & 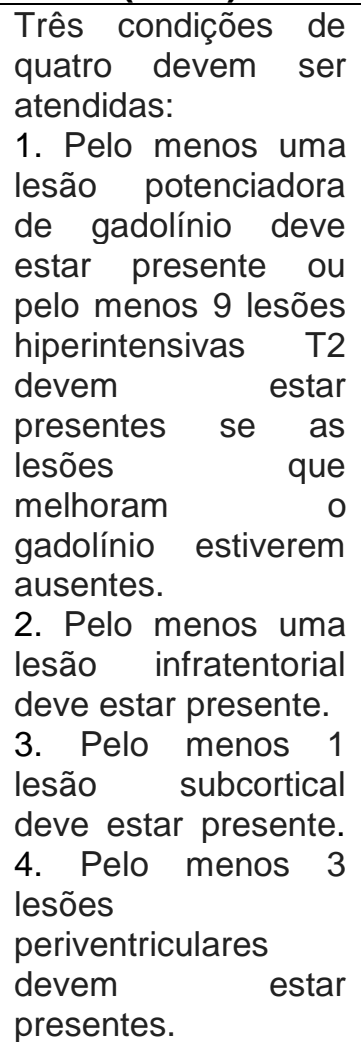 & 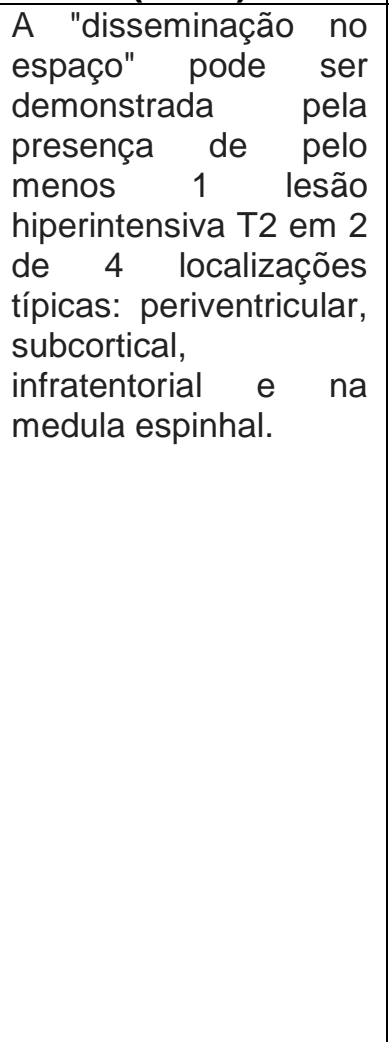 & $\begin{array}{ll}\text { A "disseminação no } \\
\text { espaço" pode ser } \\
\text { demonstrado por uma } \\
\text { ou mais lesões } \\
\text { hiperintensas que são } \\
\text { característicos da EM } \\
\text { em duas ou mais das } \\
\text { quatro áreas do SNC: } \\
\text { regiões cerebrais } \\
\text { periventriculares, } \\
\text { corticais ou } \\
\text { justacorticais } \\
\text { infratentoriais, e medula } \\
\text { espinhal. }\end{array}$ \\
\hline
\end{tabular}

O aumento de IgG no líquor de pacientes da EM foi a primeira correlação da doença com uma alteração laboratorial, a qual foi registrada no ano de 1942. Esse achado laboratorial permitiu a associação desse aumento de IgG à sua alta produção no SNC. Por isso, outra forma de auxílio ao diagnóstico da EM é a análise do líquor, onde se faz a pesquisa de alterações de lgG, já que a anormalidade mais frequente da EM é a presença de bandas IgG oligoclonais, observadas por eletroforese, onde é possível verificar bandas oligoclonais distintas provenientes da produção de anticorpos de clones de plasmócitos que possivelmente estão em proliferação no neuroeixo, levando em consideração que em indivíduos normais as IgG são oriundas do soro, ou seja, os anticorpos migram para o líquor através da BHE, mecanismo já mencionado anteriormente (PRZYBEK et al., 2015; THOMPSOM et al., 2018).

Apesar da importância diagnóstica do exame de líquor, deve ser levado em consideração que para ser compatível com a EM o exame de LCR deve demonstrar por eletroforese a presença de duas ou mais bandas, as quais devem estar ausentes ou em quantidade menor no soro, é importante ressaltar que esse é um 
achado comum em doenças inflamatórias do SNC por isso deve ser associado ao quadro clínico do paciente (PRZYBEK et al., 2015; THOMPSOM et al., 2018).

Além da $\mathrm{RM}$ e da análise do líquor, o potencial evocado visual (PEV) também é de grande importância no diagnóstico da EM, principalmente pelo fato da neurite óptica ser um sinal clínico de extrema importância no diagnóstico por ser relativamente típico na doença. O PEV pode demonstrar anormalidades até mesmo em pacientes que não apresentam sintomas de distúrbio visual, o que demonstra a sensibilidade da técnica, ao contrário dos potenciais evocados somatossensitivos e auditivos, que são pouco sensíveis, tendo, portanto menor valor diagnóstico. Portanto, o PEV é importante em casos de suspeita de EM, onde há busca de lesões subclínicas no SNC (LEOCANI et al., 2018).

\section{Tratamento com interferon-beta}

Interferon (IFN)- $\beta$, é uma terapia modificada para a doença esclerose múltipla. Tem seu efeito benéfico mostrado pela redução da severidade da doença em pacientes com EM sendo aprovado para tratamento de EM em 2015 (ENGLISH; ALOI, 2015). Os IFNs são citocinas de importante papel na defesa contra vírus e na atividade antitumoral e já demonstraram, de maneira satisfatória, esses efeitos através de culturas celulares (UCHE; GUERRERO-PLATA, 2018).

São proteínas produzidas por praticamente todas as células de vertebrados e são divididos em duas classes: IFN tipo I e IFN tipo II. O IFN- $\beta$ faz parte da família IFN-I, mas além deste, em humanos, também fazem parte: IFN-alfa (IFN- $\alpha$ ), IFNepsilon (IFN- $\varepsilon$ ), IFN-kapa (IFN- $\kappa$ ) e IFN-omega (IFN- $\omega$ ). Cada uma dessas citocinas representantes do IFN-I são codificadas por genes distintos, localizados no cromossomo 9 humano, sendo que todas possuem estrutura homóloga e se ligam a um mesmo receptor de superfície celular, o receptor de IFN-I (UCHE; GUERREROPLATA, 2018).

Apesar de inicialmente só existirem dois tipos de IFN, foram descobertas novas citocinas que podem ser classificadas como um terceiro tipo de IFN (IFN III), os chamados IFN-lambda (IFN- $\lambda$ ) 1, 2 e 3 . Estes possuem propriedades antivirais, porém se diferem dos outros IFNs e se ligam em um receptor diferente. Apesar da classificação que integra essas citocinas ao grupo IFN, podem ser classificadas como IL, sendo denominadas, nesse caso, de: IL29, IL28a e IL28b (WELLS; COYNE, 2018).

Em 1993, o Food and drugs administration (FDA) americano, autorizou o uso de IFN no tratamento da EMRR, a qual é caracterizada pela frequência dos surtos (MARZINIAK; MEUTH, 2014). Devido aos efeitos desejáveis do IFN- $\beta$ em relação à diminuição da resposta auto-imune, o medicamento é amplamente utilizado na terapêutica da EM (MELENDEZ-TORRES et al., 2017; ORTIZ et al., 2018).

Existem duas preparações diferentes de IFN- $\beta$ recombinante, o IFN- $\beta$ 1-a e IFN- $\beta$ 1-b, ambos são utilizados na terapêutica da EMRR, apresentando bons resultados em relação à diminuição de $30 \%$ dos surtos e à progressão da doença, com redução de lesões cerebrais observadas através do gadolínio à RM (FILIPINNI et al., 2017). Entretanto, com o desenvolvimento mais recente da terapia baseada no IFN, ocorreram mudanças importantes na farmacologia e no sistema de entrega da droga. O procedimento do PEGylation sitio especifica é um procedimento bem estabelecido para aumentar a estabilidade e eficácia de drogas de pequenas moléculas. A produção de PEG-IFN- $\beta-1 a$, requer adição de uma molécula de polietileno glicol no N-terminal do IFN- $\beta$-1a. Isto aumenta o tamanho da molécula de 
interferon, reduzindo a filtração renal aumentando a meia vida do IFN- $\beta$-1a (KIESEIER et al., 2015). A Poly PEG-IFN- $\beta$-1 é uma formulação com melhor perfil de segurança, melhor custo, tolerância e aderência do que as preparações anteriores de IFN- $\beta$-1a (NEWSOME et al., 2017).

O IFN- $\beta$ 1-a não se mostra eficaz no tratamento da EMSP e EMPP, sendo eficaz na forma recorrete-remitente. Já o IFN- $\beta$ 1-b é recomendado não só no tratamento de EMRR, diminuindo a frequência dos surtos (que devem assim ser considerados quando ocorrem no período de dois anos com pelo menos dois episódios de disfunções neurológicas e remissão completa ou incompleta), mas também no tratamento da forma EMSP, por reduzir a gravidade das exacerbações clínicas e a progressão da doença (MADSEN, 2017).

Os alvos do tratamento com IFN- $\beta$ na EM são: diminuição da progressão da doença, diminuição do número de surtos e tratamento de possíveis complicações como tremores, por exemplo, e o medicamento tem se mostrado eficaz nesses quesitos na maioria dos pacientes, mas apesar dos benefícios que vêm sendo apresentados por essa terapêutica, fatores como: efeitos colaterais, tempo indeterminado de tratamento e falta de uniformidade da resposta dos pacientes têm sido motivos de preocupação a muitos neurologistas, que devem ter extremo cuidado na determinação do tratamento com drogas imunossupressoras de pacientes com EM (REDER; FENG, 2014). A redução da atividade cerebral nos surtos é significante apenas no tratamento com acetato de glatiramer (medicamento também utilizado na EMRR) ou com IFN- $\beta$ 1-b, mas não no caso de tratamento realizado com IFN- $\beta$ 1-a (FILIPPINI et al., 2017).

Os efeitos colaterais provocados pela terapia com IFN- $\beta$ são grandes obstáculos no tratamento da EM, pois muitos pacientes acabam por interromper a terapia devido ao incômodo. Destaca-se a presença de anticorpos neutralizantes (NAbs) os quais reduzem a eficácia da droga e, consequentemente, dificultam a resposta ao tratamento (BERTOLOTTO et al., 2014). Na maioria das vezes esses efeitos são similares aos ocasionados pela gripe, além de febre, cefaleias, náuseas e dores musculares, sendo a febre e os sintomas gripais os mais incidentes. A depressão e a ansiedade têm se tornado relativamente frequentes (SOELBERG SORENSEN, 2017).

O IFN- $\beta$ pode predispor o paciente a infecções, dores abdominais e torácicas, reações no local da injeção, náuseas e vertigens, distúrbios sanguíneos e linfáticos, leucopenia e anemia, distúrbios gastrintestinais e pancreáticos entre outros efeitos. O IFN- $\beta$ também é contra-indicado na gravidez e em casos de epilepsia não adequadamente controlada (SOELBERG SORENSEN, 2017; ROMMER; ZETTL, 2018).

Sintomas associados à depressão vêm sendo apresentados por pacientes de EM. Embora haja muita controvérsia em considerar a depressão como um dos efeitos colaterais do IFN- $\beta$, há muitos estudos que demonstraram depressão e distúrbios psicológicos que parecem não estar associados à doença em si. (SOELBERG SORENSEN, 2017; ALBA PALÉ et al., 2017). Entretanto, os efeitos colaterais do IFN- $\beta$ 1-a são transitórios e que há baixo índice de desistência à terapêutica e enfatizam que o mesmo é bem tolerado e que seus efeitos colaterais mais frequentes são reações cutâneas locais e sintomas semelhantes aos da gripe, desaparecendo ou diminuindo após 3 a 6 meses de tratamento (SOELBERG SORENSEN, 2017; ALBA PALÉ et al., 2017). 


\section{Mecanismos de ação do interferon-beta}

O IFN- $\beta$ pode ser considerado como antagonista à produção IFN- $\gamma$, pois age inibindo sua síntese. Essa inibição é extremamente desejável para o paciente com EM, porque o IFN- $\gamma$ é responsável pela ativação de macrófagos (no caso do SNC, microglia) e pela produção de TNF, o qual tem efeito citotóxico sobre os oligodendrócitos. Esses mecanismos contribuem para a evolução da doença, principalmente através da piora em relação à apresentação de antígenos, que é um dos principais fatores ocasionadores da resposta auto-imune (SUARDÍAZ et al., 2016).

Os mecanismos de ação do IFN- $\beta$ 1-a podem ser a modulação da produção dos níveis de $\operatorname{lgG}$, aumento dos níveis de IL-10, inibição da proliferação de leucócitos, inibição de TNF- $\alpha$, estímulo ao receptor antagonista à produção de IL-1, inibição da apresentação de antígenos na microglia, diminuição da atividade de LT e regulação das moléculas de adesão e metaloproteinases, o que impede a migração dos LT (DELANEY et al., 2016).

Para que ocorra ação do IFN- $\beta$ recombinante sobre o sistema imune, este inicia um mecanismo de sinalização, que é desencadeado pela ligação ao seu receptor (SCHREIBER, 2017). Essa ligação ocasiona o rearranjo e dimerização das subunidades do receptor seguida de ativação das proteínas acopladas a essas subunidades, levando a mecanismos em cascata de auto-fosforilação e fosforilação de proteínas. É importante saber que as subunidades do receptor de IFN I estão acopladas a proteínas das famílias: tirosina quinase (TYK) e Janus activated kinase (JAK), enquanto que no receptor do IFN II estão acopladas proteínas pertencentes apenas à família JAK (ZENKE et al., 2018).

Após a ligação do IFN- $\beta$ ao seu receptor ocorrerá a auto-fosforilação das proteínas TYK 2 e JAK 1 e, posteriormente a fosforilação de proteínas da família do sinal transdutor e ativador de transcrição (STAT). Neste caso ocorrerá a formação de um heterodímero STAT 1/STAT 2, logo ocorrerá a formação de um complexo composto pelo heterodímero de STAT e o fator de transcrição: Fator 9 regulado por interferon (IRF9), o qual irá migrar ao núcleo da célula e se ligar em regiões específicas do DNA, iniciando então a transcrição de genes que respondem à indução por IFN I. A fosforilação das proteínas STAT é uma etapa de extrema importância na resposta ao tratamento com IFN, pois é essencial para a ativação da transcrição do gene. As proteínas quinase também são responsáveis pela fosforilação do STAT 1, tendo grande importância no mecanismo de sinalização mediado por IFN- $\beta$, o qual faz parte da família de proteínas quinase $C$, juntamente com os outros integrantes dos IFNs do tipo I (ZENKE et al., 2018).

A cascata de sinalização da proteína p38 pode ter um papel mais importante na geração de sinais mediados por IFN, sendo que esta é fosforilada e ativada, e é necessária para a transcrição de alguns genes induzidos por IFN I. Os diferentes mecanismos de sinalização iniciados logo após a ligação do IFN tipo I ao seu receptor são proporcionais ao efeito pleiotrópico exercido pelo IFN (SCHREIBER, 2017; ZENKE et al., 2018).

Os IFNs induzem a expressão de centenas de genes, sendo que alguns deles são induzidos tanto por IFN I como por IFN II, e outros são ativados, seletivamente, por apenas um tipo, mas essa indução não depende apenas da via JAK-STAT, pois muitas outras vias cooperam com essa para otimizar a transcrição desses genes. $O$ gene 9-27 (também chamado de IFITM1) é induzido por todos os IFNs, por exemplo, já a transcrição do gene que codifica o fator 1 indutor de hipóxia se trata de uma 
resposta mais específica em termos de tratamento da EM com IFN- $\beta$, pois este gene é induzido apenas por esta citocina, especificamente, levando em consideração que outros genes respondem a outros tipos de IFN (DELANEY et al., 2016).

No sangue periférico de pacientes após 9-15h de administração de IFN- $\beta$ recombinante, observou-se uma regulação positiva do gene "proteína A resistente do myxovirus" (MxA) em pacientes sem NAb, enquanto que a expressão desse gene não sofreu alteração em pacientes com NAb positivos. Genes funcionais de vias da resposta imune foram predominantes no grupo de genes diferencialmente expressos, 73 genes foram identificados como regulados positivamente e 29 regulados negativamente. Dentre eles o "fator ativador de célula B" (BAFF) foi um candidato importante como marcador da resposta biológica e clínica e também para a predisposição ao desenvolvimento de NAb (BERTOLOTTO et al., 2014; HARARI et al., 2015).

Acredita-se que a atividade imunomodulatória, mais do que a atividade antiviral do IFN- $\beta$, é responsável pela melhora da doença. Neste sentido, estudos têm demonstrado que o tratamento com IFN- $\beta$ altera a produção de citocinas nos pacientes com EM. Em um ensaio envolvendo pacientes com EM e indivíduos sadios, esse padrão de modificação na produção de citocinas foi observado. Os resultados apontaram que a administração endovenosa de IFN- $\beta$ em indivíduos saudáveis propiciou o aumento da proporção de LTCD4+ produtores de IFN- $\beta$, já em pacientes com EM, houve diminuição de monócitos produtores de IL-12. Foi observado também que o padrão de citocinas foi diferente nos indivíduos com EM (D'ANGELO et al., 2018).

O impacto do tratamento com IFN- $\beta$ recombinante na quimioatração de células do sistema imune foi mostrado pela monitoração da expressão de quimiocinas e seus receptores. Neste estudo foi sugerido que o aumento de quimiocinas e do receptor CCR1 nas células periféricas do sistema imune podem reduzir a quimioatração das células imunes para o SNC agindo como um efeito terapêutico do INF beta (HEGENH et al., 2016).

\section{Marcadores de resposta ao tratamento com interferon-beta}

Atualmente, o acompanhamento da resposta ao tratamento com IFN- $\beta$ nos pacientes com EM é através de exames de RM, análise do líquor e EDRR, assim como alguns sintomas e a incidência de surtos, ou seja, o aumento de lesões ao nível do SNC, assim como o aumento de surtos e sintomas como depressão, por exemplo, podem ser importantes parâmetros para acompanhamento do tratamento, avaliando a adaptação do paciente à droga e a capacidade de reversão do quadro, apresentado pelo medicamento (BERTOLOTTO et al., 2015).

Como já citado anteriormente, o tratamento com IFN- $\beta$ na EM ocasiona uma modificação no padrão das citocinas que varia de paciente para paciente, por isso a avaliação do padrão de citocinas pode também ser considerado um marcador antes do início do tratamento imunomodulador e pode sugerir se haverá eficácia no tratamento entre os pacientes (HEGENH et al., 2016).

A administração de IFN- $\beta$ no organismo faz com que o sistema imune reconheça essa molécula e produza uma resposta imune humoral a esse antígeno. Neste sentido, foi demonstrado que o tratamento prolongado com IFN- $\beta$ leva ao desenvolvimento de anticorpos que se ligam à droga, um subtipo desses anticorpos é de natureza NAb, que pode levar ao desenvolvimento de tolerância ao fármaco, sendo que esses neutralizam seu efeito, levando à reincidência dos surtos e à 
desabilidade neurológica.associado a redução da eficácia clínica do tratamento. Portanto, um importante indicador de resposta ao tratamento com IFN- $\beta$, é a presença de NAbs (BERTOLOTTO et al., 2014).

Bertolotto et al. (2015), afirmam que uma porcentagem considerável de pacientes com EMRR apresentou NAbs contra IFN- $\beta$ dos tipos 1-a e 1-b, sendo que os NAb 1-b aparecem mais rapidamente em comparação aos 1-a, e ambos são da classe IgG. Apesar dessa diferença, os efeitos provocados por esses anticorpos independem do tipo de IFN- $\beta$ usado no tratamento, ou seja, os efeitos clínicos de NAbs 1-a e 1-b são iguais. Outros biomarcadores podem ser usados para acessar a resposta do paciente. Altos níveis de IL-17 e TNFa podem indicar uma doença mais ativa. IL-25 pode exercer uma influencia positive em pacientes homens e deve ser considerado um co-modulador entre SCD40L e IL-31 (IULIA et al., 2018).

Geralmente, a perda da eficácia do fármaco, bem como a progressão da EM, ocorrem um ano, ou mais, após o aparecimento dos NAbs, diante disso, o teste da indução da molécula de MxA funciona como um importante marcador biológico para futura falha no tratamento, pois detecta, in vivo, esses anticorpos logo após o aparecimento, sendo portanto uma forma de medir o efeito biológico do IFN- $\beta$. A técnica de PCR também pode ser usada como indicador, através da análise de genes de indivíduos que possuem esses anticorpos e os que não possuem (LIBERTINOVA et al., 2017).

Entretanto, ainda não existe um critério que discrimine pacientes que respondem ou não respondem ao tratamento. Os fatores que podem contribuir para a dificuldade de se encontrar tais marcadores na literatura de EM vem da variação de desenhos experimentais (in vitro ou in vivo), formulação e regime de tratamento, critérios de inclusão e desfecho clínico.

\section{CONSIDERAÇÕES FINAIS}

$O$ tratamento da EM através da citocina IFN- $\beta$ recombinante se baseia na imunomodulação do processo de auto-imunidade, o qual é responsável pela desmielinização. Essa imunomodulação se baseia na ação antitumoral e antiviral, tendo como principal efeito a inibição de IFN- $\beta$.

Os parâmetros utilizados para o acompanhamento da resposta ao tratamento com IFN- $\beta$ dos pacientes com EM, têm auxiliado no prognóstico da doença de maneira a fornecer dados que permitem a pré-avaliação da resposta ao tratamento em relação à evolução ou à regressão da doença.

Através de parâmetros clínicos, biológicos e moleculares é possível avaliar a eficácia e as limitações do uso de IFN- $\beta$ recombinante na EM. O parâmetro clínico mais utilizado e certo para o fechamento do diagnóstico clínico da EM é a RM, embora existam outros exames clínicos, a RM permite a visualização das placas correspondentes às regiões não funcionais do SNC, mas outros tipos de exame como PEV, por exemplo, podem ser importantes para avaliação paralela dos sintomas da doença.

Um dos objetivos da pesquisa e prática clínica é o descobrimento de marcadores que possam ser correlacionados com o sucesso da terapia ou com efeitos colaterais indesejados, diante disso, o conhecimento da resposta biológica de diferentes perfis gênicos dos pacientes tratados com IFN- $\beta$ é um importante alvo a ser atingido, pois é possível dimensionar a grande diferença de perfis de resposta existente entre indivíduos tratados com este fármaco, como mostra a maioria dos estudos. 
A busca por marcadores moleculares na resposta ao tratamento com IFN- $\beta$ recombinante é uma alternativa eficaz e relativamente segura para o prognóstico de pacientes da EM tratados com essa droga, o MxA, por exemplo, é uma marcador de resposta baseado na presença de NAbs. Ainda não existem marcadores de resposta à terapia com IFN- $\beta$ específicos, o que diminui a confiabilidade de avaliação da resposta, por isso é importante a descoberta de novos marcadores mais específicos, de maneira a permitir uma maior confiabilidade no prognóstico da EM.

\section{REFERÊNCIAS}

ABBAS, A.K.; LICHTMAN, A.H.; PILLAI, S. Imunologia celular e molecular. 8. ed., Rio de Janeiro: Elsevier, 2015.

ABEM - Associação Brasileira de Esclerose Múltipla. Disponível em: <http://www.abem.org.br/index.php/esclerose-multipla>. Acesso em 20 de setembro de 2018.

ALBA PALÉ, L.; LEÓN CABALLERO, J.; SAMSÓ BUXAREU, B.; SALGADO SERRANO, P. PÉREZ SOLÂ, V. Systematic review of depression in patients with multiple sclerosis and its relationship to interferon $\beta$ treatment. Multiple Sclerosis and Related Disorders, 17:138-143, $2017 . \quad$ doi: 10.1016/j.msard.2017.07.008.

ALFREDSSON L, OLSSON T. Lifestyle and Environmental Factors in Multiple Sclerosis. Cold Spring Harb Perspect Med. May 7. pii: a028944, 2018. doi: 10.1101/cshperspect.a028944.

BERTOLOTTO, A. Evaluation of the impact of neutralizing antibodies on IFN $\beta$ response. Clinica Chimica Acta, 20;449:31-6, 2015. doi: 10.1016/j.cca.2015.02.043.

BERTOLOTTO, A.; GRANIERI, L.; MARNETTO, F.; VALENTINO, P.; SALA, A.; et al. Biological monitoring of IFN- $\beta$ therapy in Multiple Sclerosis. Cytokine Growth Factor Review, 26(2):241-8, 2015. doi: 10.1016/j.cytogfr.2014.12.002.

BERTOLOTTO, A.; CAPOBIANCO, M.; AMATO, M.P.; CAPELLO, E.; CAPRA, R.; et al. Guidelines on the clinical use for the detection of neutralizing antibodies (NAbs) to IFN beta in multiple sclerosis therapy: report from the Italian Multiple Sclerosis Study group. Neurological Sciences, 35(2):307-16, 2014.

BLANK, T.; PRINZ, M. Type I interferon pathway in CNS homeostasis and neurological disorders. Glia, 65(9):1397-1406, 2017. doi: 10.1002/glia.23154.

BOQUETT JA, ZAGONEL-OLIVEIRA M, JOBIM LF, JOBIM M, GONZAGA L JR, VERONEZ MR, FAGUNDES NJR, SCHÜLER-FACCINI L. Spatial analyzes of HLA data in Rio Grande do Sul, south Brazil: genetic structure and possible correlation with autoimmune diseases. Internacional Journal of Health Geographics., 14;17(1):34, 2018. doi:10.1186/s12942-018-0154-8.

DALTON, C. M. ; BREX, P.A.; MISZKIEL, K.A.; HICKMAN, S.J.; MACMANUS, D.G.; et al. Application of the new McDonald criteria to patients with clinically isolated syndromes suggestive of multiple sclerosis. Annals of Neurology, v. 52, n. 1, p. 47- 
53, 2002.

Disponível

em: <https://onlinelibrary.wiley.com/doi/abs/10.1002/ana.10240>.

D’ANGELO, C.; REALE, M.; COSTANTINI, E.; DI NICOLA, M.; PORFILIO, I.; et al. Profiling of Canonical and Non-Traditional Cytokine Levels in Interferon- $\beta$-Treated Relapsing-Remitting-Multiple Sclerosis Patients. Frontiers in Immunology, 4;9:1240, 2018. doi: 10.3389/fimmu.2018.01240.

DE ANGELIS, F.; PLANTONE, D.; CHATAWAY, J.; Pharmacotherapy in Secondary Progressive Multiple Sclerosis: An Overview. CNS Drugs, 32(6):499-526, 2018. doi: 10.1007/s40263-018-0538-0.

DELANEY, T.A.; MOREHOUSE, C.; BROHAWN, P.Z.; GROVES, C.; COLONNA, M.; et al. Type I IFNs Regulate Inflammation, Vasculopathy, and Fibrosis in Chronic Cutaneous Graft-versus-Host Disease. Journal of Immunology, 1;197(1):42-50, 2016. doi: 10.4049/jimmunol.1502190.

DENIC, A.; JOHNSON, A.J.; BIEBER, A.J.; WARRINGTON, A.E.; RODRIGUEZ, M.; PIRKO, I. The relevance of animal models in multiple sclerosis research. Pathophysiology, 18(1):21-29, 2011. doi: 10.1016/j.pathophys.2010.04.004. doi: 10.1016/j.pathophys.2010.04.004

ENGLISH, C.; ALOI, J.J. New FDA-Approved Disease-Modifying Therapies for Multiple Sclerosis. Clinical and Therapy, 1;37(4):691-715, 2015. doi: 10.1016/j.clinthera.2015.03.001.

FERNÁNDEZ M, MONTALBAN X, COMABELLA M. Orchestrating innate immune responses in multiple sclerosis: molecular players. Journal of Neuroimmunology. v. 25, p. 225. 2010. doi: 10.1016/j.jneuroim.2010.05.014.

FILIPPINI G, DEL GIOVANE C, CLERICO M, BEIKI O, MATTOSCIO M, PIAZZA F, FREDRIKSON S, TRAMACERE I, SCALFARI A, SALANTI G. Treatment with disease-modifying drugs for people with a first clinical attack suggestive of multiple sclerosis. Cochrane Database of Systematic Review. v.25;4:CD012200, 2017. doi: $10.1002 / 14651858$.

GIL-VAREA, E.; URCELAY, E.; VILARIÑO-GÜELL, C.; COSTA, C.; MIDAGLIA, L.; et al. Exome sequencing study in patients with multiple sclerosis reveals variants associated with disease course. Journal of Neuroinflammation, 14;15(1):265, 2018. doi: 10.1186/s12974-018-1307-1.

HAMANA, A.; TAKAHASHI, Y.; TANIOKA, A.; NISHIKAWA, M.; TAKAKURA, Y. Safe and effective interferon-beta gene therapy for the treatment of multiple sclerosis by regulating biological activity through the design of interferon-beta-galectin- 9 fusion proteins. International Journal of Pharmacy, 30;536(1):310-317, 2018. doi: 10.1016/j.jpharm.2017.12.010. Epub 2017 Dec 5.

HARARI, D.; ORR, I.; ROTKOPF, R.; BARANZINI, S.E.; SCHREIBER, G. A robust type I interferon gene signature from blood RNA defines quantitative but not qualitative differences between three major IFN $\beta$ drugs in the treatment of multiple 
sclerosis. Human Molecular Genetics, 1;24(11):3192-205, 2015. doi: 10.1093/hmg/ddv071.

HEGENH,ADRIANTOI,LESSARDCJ,MILLONIGA,BERTOLOTTOA,COMABELLAM. Cytokine profiles show heterogeneity of interferon-beta response in multiple sclerosis patients. Neurology(R) neuroimmunology \& neuroinflammation v. ;3(2):e202, 2016.

IULIA, B.L.; ANDREEA, R.; SMARANDA, M.; ZOLTAN, B.; ANCA, M.; et al. Clinical and serological biomarkers of treatment's response in patients treated continuously with Interferon $\beta-1 b$ for more than a decade. CNS \& Neurological Disorders - Drug Targets, 2018. doi: 10.2174/1871527317666180917095256.

JELCIC I, AL NIMER F, WANG J, LENTSCH V, PLANAS R, JELCIC I, et al., Memory B Cells Activate Brain-Homing, Autoreactive CD4(+) T Cells in Multiple Sclerosis. Cell. v.24. pii: S0092-8674(18)31027-4, 2018. doi: 10.1016/j.cell.2018.08.011.

KARUSSIS, D. The diagnosis of multiple sclerosis and the various related demyelinating syndromes: a critical review. Journal of Autoimmunity, 48-49:13442, 2014. doi: 10.1016/j.jaut.2014.01.022. doi: 10.1016/j.jaut.2014.01.022.

KIESEIERBC, ARNOLD DL, BALCER LJ, BOYKOA A, PELLETIER J, LIU S. Peginterferon beta-1a in multiple sclerosis: 2-year results from ADVANCE. Multiple Sclerosis journal v. 21(8):1025- 35, 2015..

LEIBOVITCH, E.C.; JACOBSON, S. Evidence linking HHV-6 with multiple sclerosis: an update. Current Opinion in Virology, 9:127-33, 2014. doi: 10.1016/j.coviro.2014.09.016.

LEOCANI, L.; GUERRIERI, S.; COMI, G. Visual Evoked Potentials as a Biomarker in Multiple Sclerosis and Associated Optic Neuritis. Journal of Neuroophthalmology, 38(3):350-357, 2018. doi: 10.1097NNO.0000000000000704.

LIBERTINOVA, J.; MELUZINOVA, E.; MATOSKA, V.; ZAJAC, M.; KOVAROVA, I.; et al. MxA mRNA decrease preceding NAb detection in IFN $\beta$-treated MS patients. Brain and Behavior, 9;7(3):e00644, 2017. doi: 10.1002/brb3.644.

LUCAS, R.M.; BYRNE, S.N.; CORREALE, J.; ILSCHNER, S.; HART, P.H. Ultraviolet radiation, vitamin $D$ and multiple sclerosis. Neurodegenerative Disease Management, 5(5):413-24, 2015. doi: 10.2217/nmt.15.33.

MA, V.Y.; CHAN, L.; CARRUTHERS, K.J.; Incidence, prevalence, costs, and impact on disability of common conditions requiring rehabilitation in the United States: stroke, spinal cord injury, traumatic brain injury, multiple sclerosis, osteoarthritis, rheumatoid arthritis, limb loss, and back pain. Archives of Physical Medicine and Rehabilitation, 95(5):986-995, 2014. doi: 10.1016/j.apmr.2013.10.032. 
MADSEN, C. The innovative development in interferon beta treatments of relapsingremitting multiple sclerosis. Brain and Behavior, 8;7(6):e00696, 2017. doi: 10.1002/brb3.696.

MARQUES, V.D.; PASSOS, G.R.D.; MENDES, M.F.; CALLEGARO, D.; LANAPEIXOTO, M.A.; et al. Brazilian Consensus for the Treatment of Multiple Sclerosis: Brazilian Academy of Neurology and Brazilian Committee on Treatment and Research in Multiple Sclerosis. Arquivos de Neuro-Psiquiatria, 76(8): 539-554, 2018. doi: 10.1590/0004-282X20180078.

MARZINIAK, M.; MEUTH, S. Current perspectives on interferon Beta-1b for the treatment of multiple sclerosis. Advances in Therapy, 31(9):915-931, 2014. doi: 10.1007/s12325-014-0149-1.

MCDONALD, W.I.; COMPSTON, A.; EDAN, G.; GOODKIN, D.; HARTUNG, H.P.; et al. Recommended diagnostic criteria for multiple sclerosis: guidelines from the International Panelon the diagnosis of multiple sclerosis. Annals of Neurology, 50(1):121-7, $2001 . \quad$ Disponível em: <https://onlinelibrary.wiley.com/doi/abs/10.1002/ana.1032>.

MCKAY, K.A.; KWAN, V.; DUGGAN, T.; TREMLETT, H. Risk factors associated with the onset of relapsing-remitting and primary progressive multiplesclerosis: a systematic review. Biomedical Research International, 2015:817238, 2015. doi: $10.1155 / 2015 / 817238$.

MELENDEZ-TORRES, G.J.; AUGUSTE, P.; ARMOIRY, X.; MAHESWARAN, H.; COURT, R.; et al. Clinical effectiveness and cost-effectiveness of beta-interferon and glatiramer acetate for treating multiple sclerosis: systematic review and economic evaluation. Health Technology Assessment, 21(52):1-352, 2017. doi: 10.3310/hta21520.

MOHAJER B, ABBASI N, PISHGAR $F$, ABDOLALIZADEH A, EBRAHIMI $H$, RAZAVIYOUN T, MOHEBBI F, ESKANDARIEH S, SAHRAIAN MA. HLA-DRB1 polymorphism and susceptibility to multiple sclerosis in the Middle East North Africa region: A systematic review and meta-analysis. Journal of Neuroimmunology. v. 15;321:117-124, 2018. doi:10.1016/j.jneuroim.2018.06.005.

NALAWADE SA, JI N, RAPHAEL I, PRATT A RD, KRAIG E, FORSTHUBER TG. Aire is not essential for regulating neuroinflammatory disease in mice transgenic for human autoimmune-diseases associated MHC class II genes HLA-DR2b and HLADR4. Cellular Immunology journal . v. 331, p.38-48, 2018. doi: 10.1016/j.cellimm.2018.05.003.

NEWSOME SD, KIESEIER BC, LIU S, YOU X, KINTER E, HUNG S. Peginterferon beta-1a reduces disability worsening in relapsing-remitting multiple sclerosis: 2-year results from ADVANCE. Therapeutic advances in neurological disorders v.10(1):41-50, 2017. 
ORTIZ, M.A.; ESPINO-PAISAN, L.; NUNEZ, C.; ALVAREZ-LAFUENTE, R.; URCELAY, E. New Life to an Old Treatment: Pegylated Interferon Beta 1a in the Management of Multiple Sclerosis. Current Medicinal Chemistry, 25(27):32723283, 2018. doi: 10.2174/0929867325666180226105612.

PEI, W.; WAN, X,; SHAHZAD, K,A,; ZHANG, L,; SONG, S,; et al. Direct modulation of myelin-autoreactive CD4+ and CD8+ $T$ cells in $E A E$ mice by a tolerogenic nanoparticle co-carrying myelin peptide-loaded major histocompatibility complexes, CD47 and multiple regulatory molecules. International Journal of Nanomedicine. 27;13:3731-3750, 2018. doi: 10.2147/IJN.S164500.

POLMAN, C.H.; REINGOLD, S.C.; EDAN, G.; FILIPPI, M.; HARTUNG, H.P.; et al. Diagnostic Criteria for Multiple Sclerosis: 2005 Revisions to the 'McDonald Criteria'. Annals of Neurology, New York, v. 58, n. 6, p. 840-846, 2005. Disponível em:<https://www.ncbi.nlm.nih.gov/pubmed/16283615>.

POLMAN, C.H.; REINGOLD, S.C.; BANWELL, B.; CLANET, M.; COHEN, J.A.; et al. Diagnostic criteria for multiple sclerosis: 2010 Revisions to the McDonald criteria. Annal of Neurology, 69(2): 292-302, 2011. doi: 10.1002/ana.22366

PRZYBEK, J.; GNIATKOWSKA, I.; MIROWSKA-GUZEL, D.; CZŁONKOWSKA, A. Evolution of diagnostic criteria for multiple sclerosis. Neurologia i Neurochirurgia Polska, 49(5):313-21, 2015. doi: 10.1016/j.pjnns.2015.07.006.

REDER A.T, FENG X. How type I interferons work in multiple sclerosis and other diseases: some unexpected mechanisms. Journal of interferon \& cytokine research V. 34(8):589-99, 2014

RIVERS, T. M. ; SPRUNT, D. H. ; BERRY, G. P. Observations on attempts to produce acute disseminated encephalomyelitis in monkeys. The Journal of Experimental Medicine, New York, v. 58, p. 39-53, feb. 1933.

ROMMER, P.S.; ZETTL, U.K. Managing the side effects of multiple sclerosis therapy: pharmacotherapy options for patients. Expert Opinion of Pharmacotherapy, 19(5):483-498, 2018. doi: 10.1080/14656566.2018.1446944.

SCHREIBER, G. The molecular basis for differential type I interferon signaling. The Journal of Biological Chemistry, 5;292(18):7285-7294, 2017. doi: 10.1074/jbc.R116.774562.

SOELBERG SORENSEN, P. Safety concerns and risk management of multiple sclerosis therapies. Acta Neurologica Scandinavica. 136(3):168-186, 2017.

SUARDÍAZ, M.; CLEMENTE, D.; MARIN-BAÑASCO, C.; ORPEZ, T.; HURTADOGUERRERO, I.; et al. Recombinant soluble IFN receptor (sIFNAR2) exhibits intrinsic therapeutic efficacy in a murine model of Multiple Sclerosis. Neuropharmacology, 110(PtA):480-492, 2016. doi:10.1016/j.neuropharm.2016.07.026. 
THOMPSON, A.J.; BANWELL, B.L.; BARKHOF, F.; CARROLL, W.M.; COETZEE, T.; et al. Diagnosis of multiple sclerosis: 2017 revisions of the McDonald criteria. Lancet Neurology,17(2):162-173, 2018. doi: 10.1016/S1474-4422(17)30470-2.

TIETZ S, PÉRINAT T, GREENE G, ENZMANN G, DEUTSCH U, ADAMS R, IMHOF B,AURRAND-LIONS M, ENGELHARDT B. Lack of junctional adhesion molecule (JAM)-B ameliorates experimental autoimmune encephalomyelitis. Brain Behavior Immunity. v.73:3-20, 2018. doi: 10.1016/j.bbi.2018.06.014.

UCHE, I.K.; GUERRERO-PLATA, A. Interferon-Mediated Response to Human Metapneumovirus Infection. Viruses,18;10(9), 2018. pii: E505. doi: 10.3390/v10090505.

WELLS, A.I., COYNE, C.B. Type III Interferons in Antiviral Defenses at Barrier Surfaces. Trends Immunology, pii: S1471-4906(18)30155-8, 2018. doi: 10.1016/j.it.2018.08.008.

WERGELAND S, RIISE T, TORKILDSEN $\varnothing$. Response to 'Seasonal variation of vitamin D and Epstein-Barr virus antibody in multiple sclerosis patients', a comment letter regarding 'Vitamin D, HLA-DRB1 and Epstein-Barr virus antibody levels in a prospective cohort of multiple sclerosis patients'. European Journal of Neurology. v.25 (9):e104, 2018. doi: 10.1111/ene.13719.

YADAV, S.K.; MINDUR, J.E.; ITO, K.; DHIB-JALBUT, S. Advances in the immunopathogenesis of multiple sclerosis. Current Opinion in Neurology, 28(3):206-19, 2015. doi: 10.1097/WCO.0000000000000205.

YSRRAELIT, M.C.; CORREALE, J. Impact of sex hormones on immune function and MS development. Immunology, 2018. doi: 10.1111/imm.13004.

ZENKE, K.; MUROI, M.; TANAMOTO, K.I. IRF1 supports DNA binding of STAT1 by promoting its phosphorylation. Immunology and Cell Biology, 2018. doi: 10.1111/imcb.12185. 